\title{
PREVENÇÃO, ADESÃO, PROMOÇÃO DE SAÚdE E REABI- LITAÇÃO SOB O ACOMPANHAMENTO TERAPÊUTICO
}

\author{
Carlos Estellita-Lins ${ }^{1}$ \\ Mariana Bteshe ${ }^{2}$ \\ Verônica Miranda Oliveira ${ }^{3}$ \\ Maria Fernanda Coutinho ${ }^{4}$ \\ Márcia Ribeiro Couto 5
}

Resumo: Este trabalho narra a gênese do acompanhamento terapêutico (AT) no Brasil, lembrando as circunstâncias históricas, sociais e filosóficas que permitiram seu desenvolvimento. Enfatiza-se a contribuição do AT na prevenção de crises, adesão ao tratamento, promoção de saúde e reabilitação de transtornos psiquiátricos. O panorama sociopolítico das últimas quatro décadas é tido por condição de possibilidade para a produção de um saber e de uma práxis correlativos ao AT, compreendido como uma modalidade híbrida de intervenção em saúde mental. Seu fértil diálogo com a psicanálise e a intervenção comunitária em saúde mental o coloca num processo ambíguo de renovação em que sua função, por um lado, consolida-se e, por outro, dispersa-se. Esta modalidade de suporte está diretamente relacionada com a Reforma Psiquiátrica em curso no Brasil. $\mathrm{O}$ artigo conclui que o suporte psicoterápico regular e as intervenções comunitárias constituem duas vertentes distintas, mas potencialmente complementares que caracterizam o AT como prática autóctone com as virtudes e defeitos reveladores do panorama local e nacional.

\footnotetext{
${ }^{1}$ Psiquiatra e psicanalista - Programa de Pós-graduação em Comunicação, Informação e Tecnologia em Saúde, Labcities, Fundação Oswaldo Cruz (Fiocruz) - Instituto de Comunicação e Informação Científica e Tecnológica em Saúde (ICICT). Avenida Brasil, 4.066, sala 709, Manguinhos, Rio de Janeiro, Brasil, Telefone: 5521 3882-9235, cefestellita@gmail.com

2 Psicóloga - Programa de Pós-graduação em Comunicação, Informação e Tecnologia em Saúde (doutoranda), Labcities, ICICT-FIOCRUZ

${ }^{3}$ Psicóloga - Programa de Pós-graduação em Comunicação, Informação e Tecnologia em Saúde (mestranda), Labcities, ICICT-FIOCRUZ; bolsista TCT4-Faperj e auxiliar técnico do grupo de pesquisa

${ }^{4}$ Psicóloga - Colaboradora do grupo de pesquisa Laboratório-Psicalangue / Instituto Fernandes Figueiras-FIOCRUZ)

5 Psicóloga - Colaboradora do grupo de pesquisa
} 
Palavras-chave: acompanhamento terapêutico; Reforma Psiquiátrica; Brasil; saúde mental

(Abstract): This article describes the genesis of psychotherapeutic accompaniment in Brazil through philosophical, social and historical circumstances which made it possible. Its contribution concerning crisis prevention, treatment adherence, health promotion and rehabilitation of psychiatric disorders is stressed. The sociopolitical scenario of the last four decades is considered condition of possibility to psychotherapeutic accompaniment's knowledge and praxis, understood as hybridization of some mental health intervention 'rationalities. The prolific dialogue with psychoanalysis and mental health community interventions places psychotherapeutic accompaniment amidst an ambiguous process of renewal which, paradoxically, consolidates but disperses its function. Psychotherapeutic accompaniment understood as a modality of mental health support is deeply related with ongoing Brazilian's Psychiatric Reform. The conclusion states that regular psychotherapeutic support techniques and community interventions constitute two different although complementary therapeutic strategies, which characterize psychotherapeutic accompaniment as a local practice with its flaws and virtues, deeply revealing national and local scenario.

Keywords: psychotherapeutic accompaniment; Psychiatric Reformist Movement; Brazil; mental health

\section{Acompanhar é apoiar}

Intervenções capazes de evitar uma internação psiquiátrica a partir da lógica do hospital-dia, fornecendo suporte, apoio e segurança no domicílio do usuário em momentos críticos do tratamento, vêm sendo frequentemente denominadas de acompanhamento terapêutico (AT). Somam-se a essas estratégias algumas tecnologias de cuidado intensivo ou de suporte para reabilitação do paciente psiquiátrico (A casa, 1991; Estellita-Lins et al., 2009; Fiorati, 2008; Manson et al., 2002; Reis Neto, 1995). O acompanhante terapêtico é um profissional de saúde mental graduado que se coloca à disposição de pacientes por períodos contínuos ou intermitentes, a durar horas ou dias, com funções indefinidas ou missão definida: proteger do risco de suicídio, viajar na solidão do feriado, acompanhar durante algum evento significativo, etc.

Medidas de suporte em domicílio têm sido estudadas desde os anos 1950 em países anglo-saxões a partir da experiência do serviço social, de lares substitutos, iniciativas de enfermagem psiquiátrica e grupos de pressão com assistência jurídica, ganhando importância à medida que aumentam a adesão ao tratamento dos pacientes e melhoram a qualidade de vida em 
transtornos psiquiátricos cronificados (Bachrach, 1996; Brimblecombe, 2003). É notório que o impacto na adesão à terapêutica depende do ambiente de recuperação e reabilitação implicado e de fatores como relação médico-paciente, eficácia e efetividade da prescrição, grau de literácia em saúde, acesso aos medicamentos e recursos, padrões de apego interpessoal, transtornos de personalidade co-mórbidos, etc. (Horne, 2004; Joosten, 2008; Jorm, 2006).

No Brasil, trabalhadores de saúde mental comprometidos com a Reforma Psiquiátrica em curso, assim como um contingente de novos atores terapêuticos, como jovens psicólogos com vocação clínica e estudantes de medicina, demonstram interesse por essas iniciativas. Cumpre notar que a prevenção em saúde mental encontra-se incluída nos objetivos do AT de modo latente ou manifesto, assim como algumas iniciativas consagradas de promoção de saúde são praticadas de modo larvar, entre elas a atenção à prática regular de exercícios físicos, aos riscos do tabagismo, alcoolismo e abuso de substâncias psicoativas; concernimento com obesidade; uma rotina de cuidados em saúde incluindo consultas regulares; a reorganização do ritmo de trabalho e lazer; e a ênfase na evitação de conflitos e na utilização de reservatórios de recursos resilientes (Cadell, 2001; Meneghel, 2000).

$\mathrm{O}$ trabalho de AT teve origem nas tentativas de enriquecer a psiquiatria clínica com aporte de recursos comunitários. Originalmente, houve forte influência da antipsiquiatria com sua preocupação com práticas antimanicomiais e programa antimedicalização. As comunidades terapêuticas em Buenos Aires (Argentina), Porto Alegre e São Paulo (Brasil) forneceram inserção institucional aos pioneiros desta prática: "amigos qualificados", auxiliares psiquiátricos e acompanhantes variados (que também foram chamados de "anjos da guarda"). Atualmente, procura-se disponibilizar medidas de suporte ao paciente em seu domicílio articulando planejamento e cuidado sem perder de vista a dimensão psicoterápica. A noção de acompanhar ganha sentido a partir da significação do termo winnicottiano holding entendido como apoio. Busca-se cumprir o ideal de modificar a vida cotidiana, tentando produzir um máximo de impacto nas rotinas existenciais e pragmáticas (Estellita-Lins et al., 2006; Figueiredo, 1999). Estas tendências do cuidado em psiquiatria, constitutivas da discussão em intervenção comunitária em saúde mental, têm sido frequentemente cumpridas pelo AT, ainda que de modo selvagem, pouco teorizado, desarticulado e frequentemente alheio ao seu potencial em pesquisa, planejamento e organização de cuidados - como destacam estudos recentes (Carvalho, 2004; Fiorati, 2008; Velozo, 2006). 


\section{A anunciação}

Ao longo dos anos 1970, durante a ditadura militar brasileira, vieram à tona denúncias contra a violência e o abandono a que estavam submetidos os pacientes internados em instituições psiquiátricas. Esta luta ganhou impulso com o movimento pela anistia aos presos políticos. Muitos profissionais que trabalhavam em hospitais, engajados na resistência contra o autoritarismo e marcados pela crítica ao modelo asilar, passaram a exercer sua militância em domínios profissionais específicos. A antipsiquiatria inglesa, a reforma psiquiátrica eurocomunista italiana e as comunidades terapêuticas argentinas forneceram interlocução, inspiração e exemplo. Os experimentos da psiquiatria de setor, com Tosquelles (1969) ou Oury (1996), acabaram chegando ao panorama intelectual brasileiro tardiamente e de modo parcial, mas foram recebidos com grande interesse (Polack, 1976). A psicanálise cooperou com este ideário a partir da teoria das relações de objeto precoces, que aproxima a clínica psicoterápica dos cuidados com crianças. Boa parte desses trabalhadores de saúde mental encontrava-se influenciada pelo prestígio da psicanálise, já cindida entre anglo-saxões e lacanianos, conforme estava organizado no Brasil. Naturalmente seria redutor associar a IPA apenas aos Freudianos Ortodoxos e Neofreudianos porque excluiria as escolas da relação de objeto (independentes, kleinianos e pós-kleinianos), a própria perspectiva culturalista de Frankfurt, e parte significativa da psicanálise francesa que não se inscreve na tradição lacaniana. Concomitantemente, na esteira dos teóricos frankfurtianos (Wiggershaus, 2002) por um lado e de Louis Althusser (1991) por outro, a esquerda recebia o conceito de Inconsciente e suas inovações como um aliado potencial, e a psicanálise institucional era desenvolvida por René Lorau (1996) e Georges Lapassade (1972; 1983) a partir da penetração dos grupos bionianos (Cunha et al., 2006; Silveira, 2009). O Instituto Brasileiro de Psicanálise, Grupos e Instituições (IBRAPSI) no Rio foi bastante representativo desta fragmentação teórica. De acordo com Russo (2002), alguns psicanalistas, como Chaim Katz, Hélio Pellegrino e Joel Birman, conquistaram espaço na imprensa ao denunciar a participação de um integrante da IPA na tortura. Havia nisso, inclusive, uma tentativa de incorporar uma crítica do papel social do psicanalista e suas posições conservadoras e apolíticas, até então hegemônicas, à prática clínica em sua totalidade.

Este novo ímpeto pode ser parcialmente tributado à análise institucional e a certas posições da antipsiquiatria, mas deve-se especialmente à versão brasileira do ensino de Jacques Lacan, mediada por sua contumaz crítica da conformidade do paciente ao seu psicanalista. Os "anos de chumbo" também foram chamados de "anos do desbunde" assinalando o prestígio das atitudes iconoclastas. Os preceitos técnicos tradicionais teriam sido adotados 
enquanto modelo normalizador, especialmente no sentido de uma adaptabilidade egóica ao modo de vida norte-americano que teria sido fomentada por psicanalistas a que Lacan (1998) se refere como o "triunvirato de Nova Iorque" (integrado por Heinz Hartmann, Ernst Kris e Rudolf Loewenstein). Cabia repensar a técnica em seu frescor de um retorno a Freud que afirmava levar "a peste" ao desembarcar na América, aquele considerado mais radical em sua abertura aos experimentos ferenczianos. Este tipo de perspectiva parece ter associado vertentes psicanalíticas que praticam um enquadramento mais flexível e menos estruturado, entendendo a transferência a partir do conceito de sujeito suposto saber, com a mobilidade espacial e a capacidade de deslocamentos clínicos do AT, bastante circunstanciais e dotados de foco imanente.

Referenciais teóricos pós-estruturalistas foram igualmente relevantes. A filosofia de 1978, descortinada principalmente sob as lentes da "História da loucura" ou de seu diálogo com Robert Castel (1984), representou um impulso em favor de novas concepções da política, da clínica e do exercício de poder. Politizou-se a vida, e com ela a própria clínica. Esta influência permitiria a articulação necessária da clínica e da política, pela denúncia do privilégio do intelectual geral no discurso da modernidade. No lugar deste intelectual engajado, cujo modelo seria Jean Paul Sartre, dedicado à luta sindical ou partidária, "re-construído" por certa visão marxista do poder que, segundo Foucault, ignorava sua capilaridade e complexidade essencial, passou-se a valorizar a figura do intelectual específico, atuando localmente nos interstícios micropolíticos (Foucault, 1972). Trabalho e sindicato, que deveriam se unir em uma consciência de classe dialeticamente superior, passavam a ser revisitados como militância unificada, imediatamente tornada responsabilidade pública e tarefa intelectual de valorização da diferença ${ }^{6}$.

A partir de Foucault, a clínica pôde ser reconhecida como forma de dominação sobre a vida, a 'desrazão' e os corpos. Igualmente, esta clínica também pode ambicionar tornar-se uma forma de atuação política, desde que aberta para a renovação e o exercício crítico (Estellita-Lins, 2007). ${ }^{7}$ Com as lutas de minorias e a "política da diferença" difundidas mais tarde pelo pós-estruturalismo, tratava-se de agir localmente e exercer um poder capilar e insidioso (revolução molecular) com ressonâncias globais (renovação molar).

\footnotetext{
${ }^{6}$ No campo da saúde mental esta valorização da diferença ganha importância na atualidade com os "disability studies" norte-americanos assim como na discussão sobre a autonomia do paciente.

7 O grupo de Roberto Machado na UFRJ foi responsável por um fecundo diálogo com Foucault no período da genealogia do poder, resultando em conferências do filósofo no Rio de Janeiro e na importante obra coletiva intitulada Da-nação da Norma, que busca realizar uma arqueologia da medicina social no Brasil (lamentavelmente este livro encontra-se fora de catálogo e sem perspectivas de reedição).
} 
Assim, compreende-se que as iniciativas de renovação psiquiátrica tendiam a ficar fora do que se encontrava intelectualmente estabelecido, excluídas do meio acadêmico ou marginalizadas. Tratava-se mais de autoexílio do que de verdadeira expulsão, o que não anula o sentimento de não-pertença.

Estruturalismo e pós-estruturalismo, uma década à frente em relação à América do Norte (Castel, 1987; Frank, 1989; Holub, 1984), foram pouco assimilados pelos profissionais de saúde mental naquele Brasil de trinta anos atrás, ainda que sob a égide de Lacan (1973; 1979), Foucault (1975; 1978; 1981), Lyotard (1991), Castoriadis (2007), Deleuze e Guattari (1972). Entretanto, à medida que estes filósofos foram assumidos como influência digna, forneceram exemplo, imagem e ideais incorporados com avidez considerável e alguma incongruência. Mais tarde, estes mesmos autores passam a se destacar em ambiente acadêmico de humanidades e letras nos Estados Unidos, infelizmente sempre longe da psiquiatria, da psicanálise e da saúde mental, de onde originalmente tomavam impulso no continente europeu. Nos EUA, ao contrário do que ocorreu no Canadá, este conjunto de referências foi originalmente tido por não-filosófico, pois a analítica da linguagem reinava, e a psicanálise, já desprestigiada, era desbancada pela psicofarmacologia da Escola de Saint-Louis (Kutchins, 1997; Luhrmann, 2001). Estes autores, ainda que lidos de modo inconsistente, não deixaram de alimentar certo senso comum e consolidar um posicionamento que se voltava para a exigência de renovação da técnica vigente na saúde mental. No contexto brasileiro, isto ocorreu em uma época de luta e contestação política em favor da democracia consoante com a Reforma Sanitária vindoura.

Em direção distinta de Foucault, mas com igual relevância e múltiplas afinidades, devem ser mencionadas as investigações de Anti-Édipo (Deleuze \& Guattari, 1972), Kafka (Deleuze \& Guattari 1975), Mil Platôs (Deleuze \& Guattari, 1980), assim como Economia libidinal, de Jean-François Lyotard (1979), que exerceram crítica feroz aos modelos heurísticos de tipo arborescente, em particular do privilégio hierárquico da síntese presente no modelo psicanalítico edipiano de Lacan, no estruturalismo linguístico saussureano e na antropologia social de Lévi-Strauss. A proposta consistiria em abandonar a inércia de um modelo de clínica do Inconsciente subordinado à histeria, percorrendo a antropologia social, a psicanálise e os territórios semiológico-estruturais, em favor de uma dispersão perspectivista ordenada a partir da esquizofrenia. Buscava-se "uma crítica das condições de possibilidade do Inconsciente", segundo Deleuze (1980, pp. 16-17). Este percurso, ainda de acordo com Deleuze (1980), exortava a um posicionamento em favor da semiótica peirceana de Hjelmslev, Labov e Bakhtin, e da liberação da figura ante o discurso (Lyotard, 2002), em favor de um pluralismo rizomático.

Com o conceito de rizoma deleuziano, trata-se de colocar gramíneas com raízes aéreas no lugar de árvores frutíferas enraizadas. Ao consumar 
uma crítica de quaisquer modelos teórico sintéticos e arborescentes, Deleuze e Guattari reivindicam novas direções para a clínica além de reconhecerem que a psicanálise já estava velha demais, mesmo em sua vertente freudo-marxista frankfurtiana (Deleuze, 1972; 1980) - eis um projeto ousado, que mesmo fracassado permanece instigante. Seria difícil descrever o fascínio que exerceu sobre atores sociais envolvidos com o campo psi no Brasil, assim como sua profunda ligação com a busca de alternativas para a clínica convencional, de que o AT testemunha indiretamente. Pode-se mencionar a reflexão de Suely Rolnik $(1995 ; 1998)$ a partir da arte de Lygia Clark e da psicanálise de Guattari como representativa destas inquietações e experimentos.

\section{Reforma(s) da(s) psiquiatria(s)}

No Brasil, a reforma psiquiátrica é um processo que surge principalmente a partir da conjuntura de redemocratização do país em fins da década de 1970, com a mesma dimensão estratégica da Reforma Sanitária, ou seja, construção de viabilidade e sustentabilidade política, social, econômica e técnica. A Constituição da República, de 1988, teve papel de destaque na consolidação destas iniciativas através da municipalização do modelo gestor. A Reforma Psiquiátrica Brasileira elege como objetivo principal a reestruturação da atenção psiquiátrica, com a substituição progressiva dos recursos manicomiais por uma rede de atenção integral composta por serviços diversificados, regionalizados e integrados à rede geral de serviços de saúde, incluindo outros recursos sociais e comunitários (Amarante, 1995; 1998; Torre, 2001). Visa-se, igualmente, à territorialização de novas práticas consoantes com os direitos humanos e à cidadania do usuário de saúde mental. $\mathrm{O}$ movimento inicial de repensar as urgências psiquiátricas foi coartado, permanecendo como conquistas somente o controle de emissão de autorizações de internação hospitalar $(\mathrm{AIH})^{8}$ e um compromisso legal de supervisão de clínicas privadas conveniadas (exercido com grande dificuldade até agora). Reconfigura-se uma tensão entre os três tipos de centros de atenção psicossocial (CAPS) propostos e a necessidade de mobilidade e fluidez da rede, possivelmente mais viável com Agentes Comunitários de Saúde (ACS) atuando como acompanhantes terapêuticos a partir da nova Estratégia de Saúde da Família (ESF).

${ }^{8}$ As AIHs são autorizações de internação hospitalar que regulam a admissão de pacientes em enfermarias conveniadas (privadas porém pagas pela União) ou enfermarias do sistema público. Sua implantação representou uma importante melhoria gerencial e programática do Sistema Único de Saúde (SUS) pois permitiu maior controle e capacidade de monitoramento. 
A complexidade destas iniciativas reside na necessidade de criar módulos assistenciais adequados do ponto de vista logístico, programático e técnico. Essa estratégia supõe operacionalidade e conexões racionalmente fundamentadas. Todavia, a proposta de uma rede por si própria não foi necessariamente capaz de informar ou determinar as práticas clínicas, nem tampouco submetê-las ao crivo da discussão científica ampla. A lógica da rede não implica em práticas de rede. De certo modo, as modificações no modelo assistencial, que era oneroso, ineficaz, clientelista e perverso, engendram esforços legítimos e criativos. Alguns pares de opostos capturados na armadilha do velho versus novo podem ser nomeados: letra da lei (portarias ou decretos) versus práticas comunitárias, hard versus soft ou ainda a técnica opondo-se ao hábito. Alguns atores envolvidos no processo têm apontado como problemas não somente uma polarização político-ideológica a ser superada, mas, sobretudo, a ameaça de uma separação indesejável entre planejamento e práxis, inerente à difícil mas necessária articulação entre as esferas federal, estadual e municipal. Aposta-se em políticas públicas no sentido de criar mediação. Soma-se, a isto, a dificuldade generalizada em criar sistemas fidedignos de informação e vigilância, manejar ferramentas epidemiológicas e admitir uma mentalidade (baseada em evidências), que ainda têm sido consideradas excessivamente medicalizantes. ${ }^{9}$

Neste contexto, o desenvolvimento do AT pode ser situado sem grande dificuldade como uma modalidade hibridizada de intervenção em saúde mental. Trata-se de uma prática autóctone, com virtudes e defeitos reveladores do panorama local e nacional. A prática do AT encontra-se ligada à Reforma Psiquiátrica quanto à sua oportunidade histórica, mas deriva de uma trajetória de modificação das formas canônicas de assistência na qual a psicanálise manteve sua autoridade de vanguarda experimental.

A Reforma Psiquiátrica Brasileira ainda claudica em uma orientação psiquiátrica consensual nas práticas de saúde mental, capaz de direcionar o exercício clínico em CAPS ou em quaisquer intervenções não-hospitalocêntricas. Neste ponto, o duro predominou sobre as tecnologias leves - a instituição antecedeu as práticas, deformando-as parcialmente. É imperioso fomentar a construção de uma rede interdisciplinar, capaz de inovações que o amplo território multicultural brasileiro demanda; que não recuse a prática médica, mas tente incorporá-la em sua posição mais estratégica e produtiva;

\footnotetext{
${ }^{9}$ Não se deve esquecer tampouco a dimensão continental do país e sua constituição multicultural sempre esquecida, além do cenário pós-colonial que foi recalcado pelo projeto modernista. Estas tensões são esperadas em um panorama de circuitos locais desmobilizados e pressões cripto-lobistas no Executivo, que caracterizam a ainda incipiente democracia brasileira, atravessada por corrupção, clientelismo e focos de violência civil endêmica. Poderíamos atribuí-los simplesmente ao advento do novo, à pressão neoliberalista ou à globalização, caso a ordem das razões não demandasse algo mais preciso.
} 
que seja efetivamente pluralista e ao mesmo tempo realize escolhas planejadas (Mehry, 2001). O processo de desospitalização, que solicita atores sociais e profissionais diversos, abre-se concomitantemente ao diálogo com práticas de AT e com a psicanálise em extensão, buscando novos interlocutores à medida que rompeu seu compasso com projetos reformistas já conhecidos. A intervenção comunitária em saúde mental, oriunda deste extrato, tem sido ignorada no âmbito do planejamento em saúde mental por motivos diversos, incluindo sua exígua representatividade em linhas de pesquisa, em congressos nacionais e no ensino universitário.

Ainda que a Reforma Psiquiátrica Brasileira tenha sido condição para o desenvolvimento de um conjunto de intervenções profundamente antimanicomiais em sua estrutura, o risco de perder sua potência de diálogo com o domínio clínico - ao afastar-se da epidemiologia contemporânea ou exortar à construção coletiva enquanto produz diretrizes estritamente administrativas e muito verticais - obriga-lhe a buscar antídotos. O perigo da conivência com concepções de poder excessivamente tradicionais existe em qualquer movimento renovador. A discussão científica constitui mais um cenário democrático do Ocidente que não pode ser evitado. Gibbons (1994) refere-se ao surgimento de um novo modo de produção do conhecimento quando são desenvolvidas pesquisas a partir da necessidade de resolver problemas práticos. Etzkowitz e Leydesdorf (1996) ressaltam que um novo contrato social (modelo da tripla hélice) entre a universidade e a sociedade (governo e empresas) tem sido negociado, bastante diferente do anterior. Latour (1994; 1995; 1998) e Woolgar (1997) pensam em redes sociotécnicas enquanto Knorr-Cetina (1982) entende o panorama cognitivo através da noção de "arena transepistêmica", em contraposição à noção de uma comunidade científica cooperativa (Sobral, 2004). O patamar de racionalidade atual em saúde pública clama por discussões dentro das tramas conceituais da eficácia, efetividade, adesão, carga global de doença (GBD), dias perdidos por enfermidade (QUALY-DALY), qualidade de vida e outros conceitos pragmáticos que podem sancionar algumas práticas de modo claro e sustentável (Almeida Filho, 2000), contudo sem deixar de manter espaço para atitudes críticas $^{10}$.

A particularidade do cenário contemporâneo acena para alianças do AT e da psicanálise em extensão capazes de renovar o panorama institucional, indo buscar contato direto com o cotidiano dos pacientes e seu sofrimen-

10 Acreditamos que o campo da saúde pública pode e deve retomar programas políticos e questões de democracia participativa sem contudo assumir argumentos ou ferramentas excessivamente dirigidas, uniformes ou abrangentes. Supomos inclusive que a pesquisa qualitativa em saúde encontra-se dotada deste potencial de problematização do cuidado e da clínica. 
to psíquico em ambiente naturalístico. Não é suficiente acabar com o manicômio ou substituí-lo. Sabemos que ele retorna de várias maneiras como nos revela o aggiornamento de que fala Robert Castel (1987). É necessário inventar uma clínica do espaço domiciliar e do cotidiano. A visita domiciliar constitui um exemplo precioso disso. A mentalidade discricionária manicomial, que pretende inexistirem qualidades na experiência da desrazão, permanece atuante em nossas emergências psiquiátricas, em unidades de pesquisa universitária e em veículos midiáticos de ampla circulação. Aprendemos com Foucault que não é o hospício que condena a desrazão e realiza o banimento da loucura. Qualquer forma de domesticação da loucura ocorrerá no interior de saberes e práticas cada vez mais civilizados como em sociedades psiquiátricas avançadas. Isto implica em reconhecer a extrema politização implícita na noção de cotidiano e reconstruir contrapoderes e resistências como cidadania legítima. Isto também exige uma vigilância racionalista para que não recusemos a inovação. Mais importante que abrir o manicômio (que sempre se fecha novamente) seria conectar algumas máquinas desejantes com máquinas cotidianas (industriais, computacionais, urbanas), buscando tematizar o cuidado, e afastando-se da noção de cultura assim como de natureza humana se for necessário. Os anjos do filme de Wim Wenders (1987), os anjos da guarda, a robótica e o suporte comunitário do acompanhante terapêutico estariam finalmente reunidos, articulando-se através de conceitos "não-mentais", afastados do psicologismo (Pelbart, 1993).

O AT progrediu, portanto, a partir de um referencial antipsiquiátrico e antimanicomial ligado ao modelo de reforma psiquiátrica até incorporar o referencial psicanalítico que prescinde do enquadramento convencional, reconhecendo-se em uma profunda transformação da noção de espaço clínico. De certo modo o acompanhante terapêutico seria capaz de repetir a clínica como paródia além de poder simulá-la como intervenção. A existência simultânea de diferentes experiências e ambições na prática clínica colaboraram para o surgimento de novas imagens do acompanhante terapêutico. Este processo de renovação ainda em curso, que problematiza sua identidade em consolidação ou, ao contrário, contribui para uma dispersão mais profunda é o cenário que nos põe diante da escolha terrível e inútil entre Charybde e Scylla. ${ }^{11}$

11 Sigmund Freud (1936) nos fala desta escolha infeliz, que aparece na literatura desde Homero até La Fontaine. Filha de Poseidon e Gaia, tendo Charybde prejudicado Hércules, é punida com o desterro para recifes traiçoeiros de onde emerge três vezes ao dia para devorar os barcos e a água do oceano. Scylla é a ninfa que, ao ingerir um falso filtro do amor, é transformada em monstro terrível, devido ao ciúme que Circe tinha de Glauco. Com suas inúmeras pernas e braços engendrava um redemoinho marítimo incontornável. Alguns situam estes perigos do mar no estreito de Messina, entre a costa da Sicília e Itália continental. 
Ao longo desta trajetória tornou-se possível atuar em reabilitação, promoção de saúde e prevenção em níveis secundário e terciário nos moldes da intervenção comunitária em saúde mental anglo-saxã incorporando, porém, questões autóctones (Czeresnia, 2003). A reabilitação pôde ser concebida como prática eminentemente promotora de saúde mental e igualmente assumida como vetor de comunicação e informação em saúde. Qualquer atuação do AT nesta vertente deu-se de modo autêntico, motivada por demandas clínicas reais, embora com exígua consciência dos atores envolvidos no processo. Paralelamente, emergiram na medicina clínica práticas de home-care que reconfiguraram papéis e acostumaram o olhar para a associação entre visita domiciliar e tecnologias de cuidado dotadas de objetivos bem delineados. Atualmente, a posição privilegiada do acompanhante terapêutico em tecnologias de visita domiciliar em saúde mental chama a atenção, domínio que pode ganhar importância estratégica no Programa Saúde da Famí$1 i a^{12}$, por exemplo, no qual é necessário reconhecer um deslocamento claro na direção da intervenção comunitária em saúde mental, demandando experiência em visita domiciliar, dinâmica familiar e psicoterapia interpessoal. O tratamento de pacientes críticos, como no risco de suicídio e de modo análogo no suporte à rotina domiciliar de autistas, revela este potencial polifônico bastante peculiar ao AT. A clinica das toxicomanias reflete também a tendência.

Lembremos que a visita domiciliar já foi um recurso exclusivo de fase não-crítica do tratamento, que se apoiava em uma antítese da tarefa clínica de tomada de decisão, pois simplesmente oferecia companhia ("acompanhava") a pacientes cronificados absolutamente desprovidos de qualquer rede de cuidados, restritos portanto à demanda legítima de escuta e respeito. Não se trata de questionar o valor destas intervenções, mas de compreender o potencial mais extenso da posição do acompanhante terapêutico como articulador-intercessor. Nesse novo recorte, o cuidado domiciliar passa a ser entendido como novo regime de acesso aos problemas que demandam soluções inéditas. Torna-se cabível entender a visita como aproximação assintótica de um

12 O programa de saúde da família, em implantação no Brasil consiste em "um projeto dinamizador do SUS, condicionado pela evolução histórica e organização do sistema de saúde no Brasil.(...) funcionando como estratégia estruturante dos sistemas municipais de saúde (...) com o intuito de reordenar o modelo de atenção no SUS. O trabalho das equipes busca comunicação e "troca de experiências e conhecimentos entre os integrantes e o saber popular do Agente Comunitário de Saúde”. (...) “As equipes são compostas, no mínimo, por um médico de família, um enfermeiro, um auxiliar de enfermagem e seis agentes comunitários de saúde. Quando ampliada, conta ainda com: um dentista, um auxiliar de consultório dentário e um técnico em higiene dental. Cada equipe se responsabiliza pelo acompanhamento de cerca de três mil a quatro mil e quinhentas pessoas ou de mil famílias de uma determinada área, e estas passam a ter co-responsabilidade no cuidado à saúde."Acesso em: 11/01/10; http://dtr2004.saude.gov.br/dab/atencaobasica.php. 
cotidiano oculto, renegado e recalcado. Movimento que acaba autorizando o acompanhante terapêutico enquanto observador clínico fidedigno, assim como agente de transformações autênticas e diretas, porquanto apoiadas em ambiente legítimo, e também ainda, como prótese flexível dos cuidados hospitalares em graus de intensidade e complexidade variável.

\section{Psicoterapia, psicofarmacologia e intervenção comunitária em saúde mental}

A despeito de pretensões hegemônicas da psiquiatria biológica, a psiquiatria clínica ou psiquiatria compreensiva permanece apoiando-se sobre seu ilustre tripé terapêutico: a terapêutica biológica, o campo das psicoterapias e as ações em intervenção comunitária em saúde mental. Na primeira base articulam-se muito bem psicofarmacologia e terapias biológicas, enquanto no segundo pé, onde predominam terapia cognitivo comportamental (TCC) e psicanálise(s) entramos em terreno conflituoso, já na terceira sustentação, verificamos um espectro variado, totalmente dependente das respectivas políticas públicas nacionais.

Grande parte das psicoterapias desenvolvidas ao longo do século XX buscou fundamentação na prática psicanalítica do grupo vienense original, no qual o conceito fundamental de transferência teve importância análoga ao de Inconsciente. No entanto, a teoria nutre-se de variantes ou exceções que não são necessariamente redutíveis à matriz operatória, quaisquer que sejam os procedimentos estruturais de redução ou homologia. O psicótico, a criança, a mulher e o selvagem constituem exemplos das tentativas de redução metapsicológica, imperfeita ou residual, que acabou transferindo inúmeros problemas, para utilizar a expressão de Imre Lakatos (1977), sem necessariamente criar novos paradigmas. Pode-se inclusive admitir que alguns impasses somente foram satisfatoriamente resolvidos através de iniciativas clínicas heterodoxas, em ruptura com a concepção transferencial hegemônica, como será o caso da teoria das relações de objeto precoces.

A feminilidade e a maternagem, assim como a gênese da subjetividade no bebê, chamaram atenção para algumas aporias da teoria psicanalítica clássica. A crítica deste dogmatismo estimulou estudos empíricos da díade e, mais tarde, da teoria do apego. A importância da criança como questão teórica e problema científico já se verifica no entre-guerras, afirmando-se durante o pós-guerra com a modificação profunda da família como instituição nuclear do capitalismo industrial. Tecnologias e estratégias de saúde pública se voltam para a criança e as modificações da família burguesa e proletária. A psicanálise será doravante forçada a revisões, com as teorias de relação de objeto precoce, e será enriquecida por uma releitura semiológico- 
-estruturalista de Freud por Lacan. Ambas exegeses terão profundas consequências para a modificação da técnica psicanalítica. De acordo com Souza (2001), com Klein, Fairbairn, Balint, Winnicott, Bion e Bowlby, assim como com Lacan e alguns discípulos, será possível ir ao encontro do paciente despreocupadamente, abandonando o setting clássico e substituindo a interpretação pelo holding, pelo cuidado ou pelo "ato psicanalítico". Em outro extremo, será pertinente tomar o paciente-sujeito-criança como objeto de estudo empírico, abandonando a metapsicologia "das profundezas" rumo ao espectro "interpessoal-intersubjetivo" - e correndo o risco de fazer mera psicologia descritiva da consciência (da pessoa ou indivíduo).

No território das psicoses, constata-se que a difusão progressiva dos neurolépticos modificou profundamente o manejo clínico-institucional dos casos, repercutindo favoravelmente nas tentativas de tratamento psicoterápico. Igualmente, a contribuição da antipsiquiatria e das novas práticas institucionais propiciou uma transformação no panorama asilar. Disciplinas como a psicologia social e a intervenção comunitária em saúde mental emergem no cenário clínico tradicional prometendo contribuições que ainda se avolumam, inspiradas, segundo Manning (1976), pelas comunidades terapêuticas de Maxwell Jones e seguidores. Hoje, a psicoterapia de pacientes críticos começa a ser re-visitada considerando que o impacto da psicofarmacologia se deu prioritariamente no controle sintomático de sintomas positivos. A prevenção do suicídio depende da detecção precoce de transtornos afetivos e o tratamento da esquizofrenia demanda intervenções imediatas para "preservar a janela terapêutica". Saúde pública, epidemiologia e saúde coletiva progressivamente articulam intervenções populacionais com o arsenal terapêutico da prática clínica centrada na pessoa e sua narrativa, prometendo ferramentas para a renovação das práticas em saúde mental.

Sabemos que ao longo do século XX a medicina ganha alcance planetário, organizada por políticas de grandes conglomerados, corporações e grupos de interesse. Sua globalização foi bastante precoce considerando que a medicina clínica moderna data da Revolução Francesa (Foucault, 1977). O financiamento da saúde torna-se mais dependente do Estado e suas práticas bastante subordinadas ao Governo mesmo nos modelos liberalistas. Esta transformação estendeu-se também à sua racionalidade intrínseca, pois um escopo maior de atuação corresponde a uma necessidade maior de controle e uma preocupação maior com o custo. Uma "nova saúde" desenha-se para novas necessidades da sociedade repartida com o mesmo apetite entre normal e patológico. Neste panorama, a preocupação social da psiquiatria revela-se atravessada pela política e por razões de governo, mas igualmente conectada aos impasses da saúde pública (Castel, 1979; Sfez, 1996), que se traduzem enquanto lutas sociais, democratização, humanização, vontade de empoderamento, políticas de minoria, necessidade de inclusão e ações afirmativas. 
As experiências do AT no Brasil e na Argentina têm caminhos distintos naquilo que se refere aos métodos empregados e aos resultados, apesar de partirem do mesmo referencial teórico. Pode-se afirmar que o hospital-dia, as experiências de comunidades terapêuticas, as iniciativas de convívio da antipsiquiatria e os novos modelos de pesquisa com crianças (e seus pais/cuidadores) tiveram um papel decisivo na formação de um repertório de intervenções ambientalistas do qual deriva o AT. As pesquisas precursoras na Tavistock Clinic (Londres, UK) com crianças, adolescentes e famílias, envolvendo a colaboração com o serviço social através da psicanálise winnicottiana e kleiniana, compõem um exemplo consistente, mas eventualmente esquecido.

Deve-se reconhecer que "experimentos" clínicos baseados em permanecer junto ao paciente, acompanhar seu sofrimento e compartilhar a experiência da loucura, angústia e estranhamento foram decisivos para que ocorresse uma mutação profunda na mentalidade de psicólogos, médicos e profissionais de saúde mental. A antipsiquiatria trouxe vigorosa surpresa, aliada à corajosa inversão do foco de atuação, com peso inquestionável. Em meio ao debate metapsicológico, as práticas investigativas com bebês oferecem sustentação para um referencial clínico ampliado que visa ao ambiente do cliente, conforme assinala Kaës (1996). A vulnerabilidade extrema passou a despertar interesse. A problemática do cuidar emerge no interior da própria técnica psicanalítica através de conceitos como espaço transicional, processos de maturação e especialização do meio-ambiente. A noção de resiliência faz convergir psicologia social e psicanálise.

$O$ fato de se instaurar algum tipo de transferência na atuação do acompanhante terapêutico assinala a importância do conceito de transferência para a relação médico-paciente, para os circuitos comunicativos institucionais ou para qualquer psicoterapia interpessoal, recolocando o problema dos desdobramentos deste efeito. O conceito de transferência, derivado de um modelo clientelista assistencial, tende a deslocar-se para o eixo cuidador-cuidado, de maior relevância em saúde coletiva, tangenciando uma clínica ampliada. Noções psicanalíticas como a cisão do objeto e a divisão do sujeito têm sido investigadas neste nexo, em que o sentido de estar ao lado, ficar junto de, ou permanecer ao alcance organiza-se preeminentemente enquanto objeto persecutório, mau, estranho ao $\mathrm{Eu}$, mas igualmente como "sujeito-suposto-saber-cuidar", "causa" e "objeto perdido".

A proximidade pode, por outro lado, ser compreendida a partir do estabelecimento da regularidade e inconstância objetal. De acordo com a teoria winnicottiana, confiabilidade e segurança são essenciais ao processo de maturação da personalidade, implicando em subsequente orientação no espaço transicional rumo à autonomia e à individuação. Sob ambas encontra-se a noção de ritmo, que está ligada à qualidade dos cuidados (Winnicott, 2000). 
Para Winnicott (2000), nos primórdios do desenvolvimento emocional o recém-nascido permanece por longos períodos em uma condição de não-integração primária, exposto a impressões diferentes e desencontradas. Em função disto depende de forma absoluta do suporte egóico, da proteção e da segurança oferecidos por outra pessoa (objeto pequeno a) que representa a alteridade (grande Outro). A mãe ou seu substituto deve estar suficientemente afinada com as necessidades do bebê, sendo capaz de percebê-las e sobretudo antecipá-las, proporcionando um ambiente seguro para ele. Trata-se de cuidados, isto é, de um holding físico e psíquico. Este cuidar típico da preocupação materna primária lhe faculta uma primeira "ilusão de onipotência", que permite ao bebê adotar gradualmente o princípio da realidade. Para que essa ilusão se realize, é preciso que o mundo lhe seja apresentado de modo compreensível e limitado, em acordo com as suas necessidades. Esta ilusão encontra-se na origem da criatividade humana e relaciona-se com noções cognitivistas como "problem solving habilities" ou "coping strategies". Em termos winnicottianos, o cuidador deve ser capaz de apresentar os objetos no momento adequado em que a criança está preparada para criá-los e vinculá-los com aquilo que é real.

Deparamos-nos aqui com a importância das falhas progressivas nos cuidados maternos que, como Winnicott (2006) bem destacou, deveriam ser suficientemente bons. Um cuidado infalível ou uma adaptação muito variável revelam-se traumáticos, o que impede a criança de viver continuamente a passagem de um estado de dependência absoluta a uma dependência relativa.

Nesse contexto, a disponibilidade do acompanhante terapêutico enquanto cuidador inspirado no anjo-da-guarda ganha relevo em um contexto de fragilidade, vulnerabilidade e adoecimento. A noção tópica de regressão, cara aos psicanalistas mais tradicionais, mostra-se exata neste ponto. Porém este cuidar será tão interpretativo quanto integrador e constitutivo.

Na clínica tradicional e nos tratamentos regularmente oferecidos, verifica-se a solidez de extremos que respeitam a dicotomia da esfera pública e privada. No consultório psicanalítico vienense original, a relação clientelista implicava em um acordo contratual duradouro, mas passível de ruptura a qualquer momento (resistência). Em um cenário oposto, mas contemporâneo da fundação da psicanálise, alienados mentais eram condenado à exclusão manicomial através de um pacto efêmero, mas que poderia ser prolongado indefinidamente (por exigências juridicas). $\mathrm{Na}$ consulta psiquiátrica, eram indefectivelmente prescritos banhos ou internamento, realizando a equação estigmatização = asilo. Quando neurolépticos e antidepressivos são incorporados ao arsenal terapêutico criam-se condições para que as esferas pública e privada mesclem-se progressivamente, confundindo seus limites a partir de novos experimentos de desenho de serviço. As intervenções em saúde mental deixam de obedecer exclusivamente à polaridade consultório/ambulatório 
privado ou hospital/clínica pública, revelando um espaço pleno de nichos e recantos especiais em que a intervenção ambiciona definir o espaço e não mais o contrário. A ênfase tem sido paulatinamente colocada na relação interpessoal, em regimes de troca (dádiva/dom) e, sobretudo, em formas de cuidar. A intervenção tende a se tornar local, parcial e estratégica, em oposição aos espaços polarizados que pressupunham modelos de atuação menos flexíveis ${ }^{13}$.

Neste sentido, pensar políticas públicas em saúde mental que valorizem prioritariamente tecnologias leves, as relações ${ }^{14}$, em detrimento daquelas pesadas, do equipamento ${ }^{15}$, pode representar o início de uma nova política do cuidar. Cumpre notar que se trata da busca de um equilíbrio sempre precário. $\mathrm{O}$ cuidado não significa afastamento da tecnologia, ao contrário, representa seu verdadeiro resgate, especialmente sob perspectiva humanizadora em domínios de baixa utilização de equipamentos tecnológicos como a saúde mental, em que recursos humanos são estratégicos.

Gilberto Freyre $(1940 ; 1998)$ nos fala de um território sem limites precisos, que une casa-grande e senzala, aproximando a lógica colonial brasileira de práticas que confundem a vida pública com a privada e a obra de Roberto DaMatta debruça-se sobre estas franjas de sociabilidade que fazem da casa brasileira um espaço bastante singular (Freyre, 1988). Seria tentador admitir o AT como um caso específico deste regime de aproximação entre a rua e a intimidade, assim como pensá-lo como uma perspectiva privilegiada na tarefa de investigação desta experiência.

\section{Reabilitar e resistir}

A noção de reabilitação psicossocial representa uma tensão intrínseca ao campo da Reforma Psiquiátrica. Difundida e de fácil aceitação, permanece, contudo, uma palavra de ordem desprovida de conceito ou idéia. O crivo da eficácia lhe é estranho. Sua especificidade parece diluir-se bastante quando observamos o volume de reflexões acerca da inclusão, estigmatização, deficiência(s), necessidades especiais, resiliência, esperança, literacy, entre outras conceituações que ziguezagueiam entre saúde coletiva e assistência. Como restabelecer a saúde ou funcionalidade dos pacientes sem suprimir

13 Pode-se admitir a contraposição do molar ao molecular, como na reflexão de Guattari e Deleuze, ou uma tensão entre equipamentos coletivos de saúde e privados/máquinas de curar, como formularam Murard e Fourquet.

14 Formação de pessoal, treinamento, educação continuada, práticas de humanização, cuidado e intervenção.

15 Legislação, administração, proliferação da rede, unidades assistenciais rígidas, edificações, instituições. 
conflitos? Como adequar sem ocultar divisões intrínsecas à sociedade e à subjetividade? A relação entre psicopatologia e saúde mental mostra-se ainda complexa quando se trata da intervenção comunitária em saúde mental ou de políticas de saúde mental. Isto exige que não sejam abandonados conceitos promissores e talvez fundamentais como normatividade, autopoiese, espaço transicional, nem tampouco esquecidas noções operatórias como resiliência, plasticidade ou ainda adaptabilidade. Torna-se imperioso dispor de uma reflexão capaz de trabalhar com tensões permanentes e insolúveis sem, contudo, desconectar-se de aspectos pragmáticos.

A partir da obra de Canguilhem (1978; 1989), vigora a preocupação em pensar os fenômenos biológicos adaptativos enfatizando sua ressonância normativa, que em última análise constitui uma reflexão ético-política. Esta perspectiva oriunda da história das ciências, que influencia bastante Foucault, apresenta-se como solução engenhosa para alguns meandros técnicos da psiquiatria social, especialmente porque evita adotar a consciência ou o sujeito como critérios absolutos. O conceito de normatividade do vivente pressupõe que valores como saúde e doença troquem frequentemente de posição em função da incapacidade do organismo em criar novas normas ou novos parâmetros adaptativos. A capacidade normativa do vivente, que tenta impor ou inventar novas normas, não deve ser entendida como conformidade com determinado meio ambiente (biológico ou social), porque recusa qualquer noção ingênua de adaptação que confunda sociedade com meio externo ou que admita uma adequação incondicional à circunstâncias fora do devir. Uma perspectiva de três ou mais ecologias toma impulso a partir disto.

Pode-se supor que a noção de resiliência tal como vem sendo trabalhada e deslocada de seu solo epidemiológico original, descreve uma aptidão endógena para resistir ou para não-sucumbir quando o indivíduo é confrontado com um arranjo complexo de fatores etiológicos ou de risco. Alguns indivíduos possuem a capacidade de sofrer dano, estresse ou insulto fletindo-se sem quebrar, recuperando-se mais rapidamente ou permanecendo inalterados (Connolly, 2000; Masten, 2004; Patterson, 2002; Richardson, 2002a, $2002 b$ ). Esta hipótese fornece elementos para intervenções que se construam em plena consciência de seus impasses metodológicos, mas que estejam atentas para a tarefa da reabilitação compreendida enquanto estado de conflito e negociação permanente, como é o caso do cotidiano da intervenção comunitária em saúde mental, incluindo o AT.

O cuidado derivado do campo transicional, de acordo com Winnicott (1983), implica em uma potência criativa e formadora de ilusão enquanto espaço potencial, instância doadora de subjetividade. A mãe, especialização do meio ambiente (que será emulada em várias formas de cuidado), é capaz de proteger, facilitar e alavancar inúmeras atividades de sua criança permitindo uma ilusão de capacidade ou mesmo onipotência que adquire valor 
organizador para o processo de subjetivação e de maturação (Winnicott, 1983). Quando se formula o cuidado como dispositivo civilizatório, humanizador e subjetivante configura-se uma vantagem sobre programas tecnicistas de atenção em saúde ou ainda sobre motivos abstratos de transformação radical dos sistemas de cuidado em saúde mental. Nestes o cuidar é simplesmente tarefa, permanecendo impessoal e indeterminado, enquanto o cuidar do espaço potencial winnicotiano consiste em transformar o entorno em dispositivo especializado valorizando a função de companhia.

A definição de reabilitação no Dicionário da Língua Portuguesa de Aurélio Buarque de Holanda (1985, p. 1432) - "ato ou efeito de reabilitar-se; recobramento de crédito, de estima, ou do bom conceito perante a sociedade, restauração à normalidade, ou ao mais próximo possível dela, de forma e de função alteradas por algum tipo de lesão" - não mostra suficiente ênfase em noções como apoio ou suporte. Para McQuistion et al. (2000), assim como para Bachrach (1996), a reabilitação psicossocial pode ser pragmaticamente definida como uma atitude terapêutica cujo fim último seria o desenvolvimento de capacidades por parte do portador de sofrimento psíquico; dessa forma, calcar-se-ia em um processo de aprendizagem e acolhimento viabilizado por um ambiente que lhe dê suporte. Saraceno (1996, p. 43), por sua vez, entende que a reabilitação "coincide com a necessidade de encontrar estratégias de ação em relação mais real com as variáveis que parecem implicadas". Ambas as assertivas entendem a reabilitação como processo estratégico e multidimensional de intervenção, reconhecendo sua complexidade socioambiental. Seria cabível pensarmos em redes sociais quando aproximamos conceitos como estímulo, meio ambiente, cultura e informação. Os objetivos da reabilitação consistiriam em ajudar indivíduos "com transtornos mentais persistentes e severos a desenvolver habilidades sociais, intelectuais e emocionais necessárias para viver, aprender e trabalhar na comunidade com a menor quantidade possível de suporte profissional" (Saraceno, 1996, p. 43). O processo de saúde-doença demanda ao próximo uma mistura paradoxal de apoio e autonomia na reabilitação.

A reabilitação suscita estudos epidemiológicos. Há evidência suficiente para sustentar intervenções capazes de minimizar danos e melhorar o prognóstico em casos de disfunção, deficiência e transtornos psiquiátricos diversos. Em vários países, sistemas de saúde fomentam iniciativas com equipes multidisciplinares, intervenções domiciliares e especialistas em reabilitação. Torna-se relevante integrar programas diferentes como psicoeducação familiar, emprego supervisionado ou competitivo, trabalho assistido, manejo de caso, treinamentos de autogerenciamento de crise, serviços voltados para diagnóstico dual/comorbidades, etc. Esta integração facilita acesso e adesão aos tratamentos, maior comunicação entre atores envolvidos, planejamento compreensivo do tratamento, intervenções consistentes e maior 
atenção à qualidade de vida. Necessidades em reabilitação começam a ser nomeadas e remanejadas, sem que o dispositivo de acompanhamento-apoio se torne desnecessário ou tenha sido superado pela progressão na complexidade dos cuidados exigidos.

Quando Saraceno (2001) propõe uma análise crítica dos quatro modelos conceituais operantes em reabilitação psiquiátrica, tenta demonstrar que se trata sempre de um paradigma no qual a psiquiatria mobiliza um conjunto de estratégias de entretenimento, ou seja, de manutenção do paciente e do cuidador dentro de um processo de autorreprodução da doença e da cura. A reabilitação psicossocial em sua proposta deve forçar os lugares da ação, multiplicar os atores em ação, articular objetivos, engendrando uma abertura das portas deste "dentro" que é a psiquiatria asilar ao mostrar suas aporias. Se a reabilitação for utilizada como recurso para entender, inovar e estender cuidados, é possível ampliar a prática, na qual psiquiatria clínica e saúde mental se rearticulem.

Em lugar da hegemonia dos modelos médico-psiquiátricos, é possível buscar respostas na vida, no sofrimento e nas necessidades complexas dos sujeitos. Contudo, cada vez mais este direcionamento deve utilizar o conhecimento positivo adquirido com ferramentas epidemiológicas e de saúde coletiva, rearticulando-se com o campo biomédico. Cada vez menos se pode desdenhar o corpus de conhecimentos baseados em evidência ou as novas racionalidades clínicas emergentes. Sabemos que a vida cotidiana comporta uma psicopatologia intuitiva e também uma terapêutica selvagem, na qual soluções não provêm necessária ou exclusivamente do equipamento médico-sanitário (McQuistion et al, 2000). A clínica psiquiátrica converge rumo ao respeito pela experiência singular de cada paciente. A vocação do acompanhante terapêutico enquanto anjo da guarda do cotidiano o qualifica precisamente para este desafio.

Seria legítimo admitir três pilares da práxis de reabilitação: práticas na construção material do exercício de direitos, práticas no desenvolvimento de trocas interpessoais e sociais e práticas de solidariedade (Saraceno, 2001). Simplesmente viver em uma casa com autonomia transforma-se uma forma sofisticada de reabilitação, além de constituir um desfecho muito positivo, pois casa (lar, domicílio) implica em exigências de identidade, em manutenção de espaços íntimos, redefinição da experiência público/privado, em construção de circuitos de rotina e no confronto com as dificuldades do cotidiano. A casa e suas vizinhanças precisam ser vistas como lugares de saída, mas também de chegada no processo de reabilitação. O espaço domiciliar corresponde a uma exigência fundamental do ser humano. Trata-se de pensar a reabilitação enquanto re-construção da existência. O lar inclusive tem se revelado um nicho privilegiado de pesquisa em saúde pública à medida que $\mathrm{a}$ cotidianidade mostra-se uma noção cheia de significado na vida contempo- 
rânea. O surgimento de megacidades e o processo de urbanização generalizado indicam que formas de adoecimento e de busca de saúde não deveriam ser desvinculadas da experiência moderna do andarilho urbano (sem-teto, mendigo) - institucionalmente domiciliado, porém errante em sua adaptação psíquica. A rua não se opõe à casa, mas em verdade a duplica ou rearticula (A Casa, 1991). A oposição mais pregnante está efetivamente situada entre os dois pólos do público e do privado: o binômio hospício-hospital opondo-se à qualquer forma de intimidade domiciliar.

\section{Para concluir}

Uma lógica de cuidados tende a ser muito mais sensível a esta fronteira do que as prescrições convencionais. $\mathrm{O}$ enigmático processo de procura ou aceitação de cuidados também se mostra carente de novos modelos analíticos em intervenção comunitária em saúde mental. Muitas vezes força-se a utilização de uma concepção psicanalítica contratual que permanece inadequada face à variedade das situações possíveis. Quando adotamos conceitos mais amplos como itinerário terapêutico ou trajetória de doença, levamos em consideração aspectos cruciais da prática do acompanhante terapêutico como a capacidade de reconhecimento de problemas, o início do processo de cuidados intensivos, o zelo na adesão ao tratamento e as descontinuidades imanentes ao curso oscilante de muitos transtornos.

O elo estigma-cuidado é outro aspecto importante na instauração de cuidados de um paciente potencialmente cronificado. Além do estigma social, reconhecido na discriminação e exclusão, tem sido valorizado o problema da autoestigmatização, entendido em sua dimensão cognitiva de recusa e afastamento (Lauber, 2004). As habilidades sociais, o desempenho interacional, suporte ao emprego apoiado (Crowther, 2001) e outras dimensões integradoras podem igualmente ser supervisionados, treinados e aperfeiçoados durante uma intervenção clínica de AT.

O AT representa considerável deslocamento na posição tradicional dos agentes de reabilitação, pois dissemina intervenções no tecido social com maior agilidade e precisão. Opera a partir de problemas. Sua proximidade aos problemas enfrentados pelo usuário enseja maior respeito pela singularidade clínica ou pelo desejo do sujeito. O espaço de intervenção é integralmente constituído pela vida cotidiana. A cidadania e o empoderamento constituem linhas de fuga muito nítidas para todos os objetivos ambicionados, incluindo a vida cotidiana a ser facilitada pela observação-participação sistemática, exercida em ambiente naturalístico e mediada pela experiência psicoterápica dos cuidadores. A imanência substitui a virtualidade das campanhas preventivas. 
Este novo profissional que passa a compor equipamentos leves e coletivos de saúde mental pretende-se fundamental na efetuação daquilo que seria central no movimento de Reforma, ou seja, substituir definitivamente o manicômio por nova(s) clínica(s) que priorize(m) o cotidiano do paciente, buscando no espaço social elementos para uma verdadeira reabilitação e para a esperada redefinição de reabilitação. A intervenção torna-se local e estratégica, em contraposição aos espaços polarizados que pressupunham modelos menos flexíveis. A possibilidade de uma clínica verdadeiramente nômade, que não depende de instituições, construções, contratos ou portarias do ministério da saúde começa a desenhar-se insidiosamente.

Podemos concluir postulando uma disjunção que parece verdadeira: ou o AT encontra-se em uma encruzilhada e perecerá em função de sua indefinição essencial ou constitui uma interface privilegiada entre psicoterapia e intervenção comunitária em saúde mental capaz de oferecer recursos especiais no plano dos cuidados ministrados. A segunda opção pode dialogar com a Programa Saúde da Família planejado no país. Esta situação peculiar ao Brasil contemporâneo motiva indagações e demanda novos estudos sob diferentes pontos de vista. O AT situa-se de fato em uma tradição psicanalítica de cuidado, singularização e supervalorização da experiência clínica. $\mathrm{O}$ AT também se insere, de direito e de fato, em um dispositivo de cuidados, institucionais ou não, que se organiza paulatinamente enquanto intervenção comunitária em saúde mental, sobretudo a partir de seu comércio com a Reforma Psiquiátrica em curso. Atualmente pode-se entender o AT em duas acepções distintas e talvez suplementares. Por um lado, como trabalho regular com psicóticos, deprimidos, bipolares e pacientes fronteiriços em uma dimensão psicoterápica com predominância do instrumental teórico psicanalítico. Por outro, concebe-se o AT como catalisador de iniciativas discretas de cuidado e da utilização de protocolos clínicos em amplas áreas de atuação em saúde mental (incluindo até mesmo interconsulta ou psiquiatria de ligação). Ocorre um predomínio da psicanálise no primeiro modelo e das intervenções comunitárias no segundo. Ambas as diretrizes são relevantes, plenas de consequências e repercussões no campo clínico contemporâneo. O AT serve ao dispositivo médico-sanitário do ponto de vista de seus objetivos e fins, contudo nutre-se de um referencial psicodinâmico no que respeita seu processo. Nisso reside sua particularidade e diferença frente às práticas comunitárias mais frequentes em países (G-8) cuja reforma se deu mais cedo e de forma mais abrangente.

\section{Colaboração:}

Couto M.R., Coutinho F. e Oliveira V.M. participaram das discussões teóricas, de campo e da estruturação inicial dos argumentos, além da primei- 
ra fase de redação. Bteshe, M. participou de discussões ulteriores e da redação e finalização do texto. Estellita-Lins C.E. participou igualmente em todas as etapas de elaboração do artigo.

\section{Referências}

A Casa (1991). A rua como espaço clínico. São Paulo: Editora Escuta.

Althusser, L. (1991). Freud e Lacan - Marx e Freud. Rio de Janeiro: Editora Graal.

Amarante, P. (1995). Novos sujeitos, novos direitos: o debate sobre a reforma psiquiátrica no Brasil. Cad. Saúde Públ., 11, 491-494.

Amarante, P. (1998). Psiquiatria social e reforma psiquiátrica. Rio de Janeiro: Editora Fiocruz.

Bachrach, L. L. (1996). Psychosocial rehabilitation and psychiatry: what are the boundaries? Canadian Journal of Psychiatry, 41, 28-35.

Brimblecombe, N., O’Sullivan, G., \& Parkinson, B. (2003). Home treatment as an alternative to inpatient admission: characteristics of those treated and factors predicting hospitalization. Journal of Psychiatric and Mental Health Nursing, $10,683-687$.

Buarque de Holanda, A. (1985) Dicionário da língua portuguesa. Rio de Janeiro: Nova Fronteira Editora.

Cadell, S., Karabanow, J., \& Sanchez, M. (2001). Community, empowerment, and resilience: paths to wellness. Can J Commun Ment Health, 20(1), 21-35.

Canguilhem, G. (1978). O Normal e o patológico (2a ed.). Rio de Janeiro: Forense

Universitária.

Canguilhem, G. (1989). Études d'histoire et de philosophie des sciences (5ème ed.). Paris: Vrin.

Carvalho, S. S. (2004). Acompanhamento terapêutico: que clínica é essa. São Paulo: Annablume.

Castel, R., Castel, F., \& Lovell, A. (1979). La societé psychiatrique avancée. Le modèle americain. Paris: Bernand Grasset.

Castel, R. (1984). Les aventures de la pratique. Le débat, 41, 41-51.

Castel, R. (1987). A gestão dos riscos. Da anti-psiquiatria à pós-psicanálise. Rio de Janeiro: Francisco Alves.

Castoriadis, C. (2007). A Instituição imaginária da sociedade. São Paulo: Paz e Terra.

Crowther, R., Marshall, M., Bond, G. R., \& Huxley, P. (2001). Vocational rehabilitation for people with severe mental illness. Cochrane Database of Systematic Reviews (CD003080).

Cunha, A. d. A. G. d., Dorna, L. B. H., \& Rodrigues, H. d. B. C. (2006). Uma contribuição à história da análise institucional no Brasil através de depoimentos orais: o setor de psicologia social da Universidade Federal de Minas Gerais (UFMG) nas décadas de 1960 e 1970. Mnemosine, 2(1), 2-11. 
Czeresnia, D., \& Freitas, C. M. d. (Eds.). (2003). Promoção da saúde: conceitos, reflexões, tendência. Rio de Janeiro: Editora Fiocruz.

Damatta, R. (1988). A casa e a rua: espaço, cidadania, mulher e morte no Brasil. Rio de Janeiro: Rocco.

Deleuze, G., \& Guattari, F. (1972). L'Anti-Oedipe. Paris: Minuit.

Deleuze, G. \& Guattari, F. (1975) Kafka: por uma literatura menor. Rio de Janeiro: Imago.

Deleuze, G., \& Guattari, F. (1980). Mille plateaux. Paris: Minuit.

Estellita-Lins, C., Oliveira, V. M., \& Coutinho, M. F. (2006). Acompanhamento terapêutico: intervenção sobre a depressão e o suicídio. Psychê, X(18), 151$-166$.

Estellita-Lins, C. E. (2007). Michel Foucault e a clínica. In A. Queiróz. e N. Velazco e Cruz (Eds.), Foucault hoje? (1a ed., Vol. 1, pp. 150-161). Rio de Janeiro: 7 letras \& PPGGC/UFF.

Estellita-Lins, C., Oliveira, V. M., \& Coutinho, M. F. (2009). Clínica ampliada em saúde mental: cuidar e suposição de saber no acompanhamento terapêutico. Ciênc. saúde coletiva, 14(1), 195-204.

Etzkowitz, H., \& Leydensdorff, L. (1996). Emergence of a triple - helix of university - industry-government relations. Science and Public Policy, 23(5).

Figueiredo, A. C. (1984). Estratégias de difusão do movimento psicanalítico no Rio de Janeiro. PUC-RJ, Rio de Janeiro.

Figueiredo, A. C., Libério, M., Gomes, M. P. C., \& Albuquerque, P. (Eds.). (1999). Cadernos IPUB. Práticas ampliadas em saúde mental: desafios e construções do cotidiano (Vol. 14). Rio de Janeiro: UFRJ.

Filho, N. d. A. (2000). O conceito de saúde: ponto-cego da epidemiologia? Revista Brasileira de Epidemiologia, 3 (1), 4-20.

Fiorati, R. C., \& Saeki, T. (2008). O acompanhamento terapêutico na internação hospitalar: inclusão social, resgate de cidadania e respeito à singularidade. Interface. Comunicação, saúde, educação, 12(27), 763-772.

Foucault, M., \& Deleuze, G. (1972). Les Intellectuels et le pouvoir. L'Arc.

Foucault, M. (1975). Doença Mental e psicologia. Rio de Janeiro: Tempo Brasileiro.

Foucault, M. (1977). O Nascimento da clínica. Rio de Janeiro: Forense Universitária.

Foucault, M. (1978) A História da loucura na idade clássica. São Paulo: Perspectiva.

Foucault, M. (1981). Microfísica do poder. Rio de Janeiro: Graal.

Frank, M. (1989). What is neostructuralism? Minneapolis: University of Minnesota Press.

Freud, S. (1936). Sixiéme conférence: eclaircissements, applications, orientations. In: Nouvelles conférences sur la psychanalyse. (pp. 192-193). Paris, Gallimard.

Freyre, G. (1940). O mundo que o português criou: aspectos das relações sociais e de cultura do Brasil com Portugal e as colonias portuguesas. Rio de Janeiro: José Olympio Editora.

Freyre, G. (1998). Casa-grande e senzala. Rio de Janeiro: Editora Record. 
Gibbons, M. (1994). The New Production of knowledge: the dynamics of science and research in contemporary societies. London: Sage.

Holub, R. C. (1984). Politicizing post-structuralism: french theory and the left in the Federal Republic and in the United States. The German Quarterly, 57(1), 75-90 .

Horne, R., Graupner, L., Frost, S., Weinman, J., Wright, S. M., \& Hankins, M. (2004). Medicine in a multi-cultural society: the effect of cultural background on beliefs about medications. Social Science and Medicine, 59(6), 1307-1313.

Joosten, E. A. G., DeFuentes-Merillas, L., de Weert, G. H., Sensky, T., van der Staak, C. P. F., \& de Jong, C. A. J. (2008). Systematic review of the effects of shared decision-making on patient satisfaction, treatment adherence and health status. Psychotherapy and Psychosomatics, 77(4), 219-226.

Jorm, A. F. (2006). Research on mental health literacy: what we know and what we still need to know. Australian and New Zealand Journal of Psychiatry, 40, 3-5.

Kaës, R. (1996). Realité psychique et souffrance dans les Instituitions. In R. Kaës (Ed.), L'instituition et les instituitions. Études psychanalytiques. Paris: Dunod.

Knorr-Cetina, K. (1982). Scientific comunities or transepistemics arenas of research? A critique of quasi economic models of science. Social Studies of Science, 12 .

Kutchins, H., \& Kirk, S. A. (1997). Making us crazy - DSM: the psychiatric bible and the creation of mental disorders. New York, London: The Free Press.

Lacan, J. (1973). Le Seminaire. Les quatre concepts fondamentaux de la psychanalyse (Vol. 11). Paris: Seuil.

Lacan, J. (1979). O Seminário. Os escritos técnicos de Freud. 1953-1954. Rio de Janeiro: Zahar.

Lacan, J. (1998) A Direção da cura e os princípios de seu poder. In: Escritos. Rio de Janeiro: Jorge Zahar.

Lakatos, I. (1977). The methodology of scientific research programmes: philosophical papers. Volume 1. Cambridge: Cambridge University Press

Lapassade, G. (1983). Grupos, organizações, instituições. Rio de Janeiro: Francisco Alves.

Lapassade, G., \& Lorau, R. (1972). Chaves da sociologia. Rio de Janeiro: Civilização Brasileira.

Latour, B. (1994). Sociology without object - notes on interobjectivity. Sociologie Du Travail, 36(4), 587-607.

Latour, B. (1995). Le métier de chercheur: regard d'un anthropologue. Paris: INRA.

Latour, B. (1998). Media, technology and society - a history, from the telegraph to the Internet. Tls-the Times Literary Supplement (4970), 5-5.

Latour, B., \& Wolgar, S. (1997). A vida de laboratório. Rio de Janeiro: Relume-Dumará.

Lauber, C., Nordt, C., Falcato, L., \& Rossler, W. (2004). Factors influencing social distance toward people with mental illness. Community Mental Health Journal, $40(3), 265$. 
Lorau, R. (1996). A análise institucional. Petrópolis: Vozes.

Luhrmann, T. M. (2001). Of two minds. New York: Vintage Books.

Lyotard, J.-F. (1979). Economia libidinal. Madrid: Editorial Saltés.

Lyotard, J.-F. (1991). Derive a partir de Marx et Freud. Paris: Galilee.

Lyotard, J.-F. (2002). Discours, figure. Paris: Klincksieck

Manning, N. (1976). Values and practice in the therapeutic community. Human Relations, 29(2), 125-138.

Manson, F., Rossi, G., Pulice, G., Frank, M. L., Alderete, S., Dragotto, P., et al. (Eds.).

(2002). Eficacia clínica del acompañamiento terapéutico. Buenos Aires:

Editorial Polemos.

Masten, A. (2004). Regulatory processes, risk, and resilience in adolescent development. Ann N Y Acad Sci, 1021, 310-319.

McQuistion, H.L., Goisman R.M. \& Tennison C.R. (2000). Psychosocial rehabilitation: issues and answers for psychiatry. Community Mental Health Journal, 36, 605-616.

Meneghel, S., Armani, T., Severino, R., Garcia, A. M., Mafioleti, B., \& Fochi, E. (2000). Cotidiano violento: oficinas de promoção em saúde mental em Porto Alegre. Ciênc. saúde coletiva, 5(1), 193-203.

Merhy, E. E. (2000). Um ensaio sobre o médico e suas valises tecnológicas. Contribuições para compreender as reestruturações produtivas do setor Saúde. Interface. Comunic, Saúde, Educ., 109-116.

Oliveira, C. L. M. V. d. (2002). A historiografia sobre o movimento psicanalítico no Brasil. Rev. Latinoam. Psicop. Fund., 3, 144-153.

Oury, J. (1996). Psicanálise e psiquiatria e psicoterapia institucionais. In P. Kaufmann (Ed.), Dicionário enciclopédico de psicanálise. O legado de Freud e Lacan. Rio de Janeiro: Jorge Zahar Editor.

Patterson, J. (2002). Understanding family resilience. J Clin Psychol, 58(3), 233$-246$.

Pelbart, P. P. (1993). A nau do tempo-rei: sete ensaios sobre o tempo da loucura. Rio de Janeiro: Imago.

Polack, J.-C., \& Sivadon, D. (1976). La borde ou le droit à la folie. Paris: Calmann-Lévy.

Reis Neto, R., (1995). Acompanhamento terapêutico: emergência e trajetória histórica de uma prática em saúde mental no Rio de Janeiro. não-publicado dissertação de mestrado, PUC, Rio de Janeiro.

Richardson, G. (2002). The metatheory of resilience and resiliency. J Clin Psychol, 58(3), 307-321.

Richardson, G., \& Waite, P. (2002b). Mental health promotion through resilience and resiliency education. Int J Emerg Ment Health, 4(1), 65-75.

Rolnik, S. (1995). Malaise chez la différence. Chimères, 25.

Rolnik, S. (1998). Subjetividade antropofágica. In P. Herkenhoff \& A. Pedrosa (Eds.), Arte contemporânea brasileira: um elentre Outro/s (pp. 128-147). São Paulo: Fundação Bienal de São Paulo. 
Russo, J. (2002). O mundo psi no Brasil. Rio de Janeiro: Jorge Zahar editor.

Saraceno, B. (1996). Reabilitação psicossocial: uma estratégia para a passagem do milênio. In: PITTA, Ana Maria Fernandes (Ed.). Reabilitação psicossocial no Brasil. São Paulo: Hucitec.

Saraceno, B. (2001). Libertando identidades. Rio de Janeiro: Te Corá Editora.

Silveira, F. d. (2009). O grupo e a institucionalização do movimento analítico brasileiro. Revista da SPAGESP, 10, 11-18.

Sobral, F. (2004). Desafios das ciências sociais no desenvolvimento científico e tecnológico contemporâneo. Sociologias, 6(11), 220-237.

Souza, O. (2001). Nota sobre algumas diferenças na valorização dos afetos nas teorias psicanalíticas. In: Bezerra Jr, B. e Plastino, C. A. (Eds.) Corpo, afeto, linguagem: a questão do sentido hoje. Rio de Janeiro: Marca D'água.

Sfez, L. (1996). A saúde perfeita: crítica de uma nova utopia. São Paulo: Unimarco-Loyola.

Torre, E. H. G. \& Amarante, P. (2001). Protagonismo e subjetividade: a construção coletiva no campo da saúde mental. Ciência \& Saúde Coletiva, 6(1), 73-85.

Tosquelles F. (1969). Que faut-il entendre par psychothérapie institutionnelle? L'Information Psychiatrique., 45 (4), 377-384.

Velozo, R. S. \& Serpa Júnior, O. D. (2006). O acompanhante terapêutico "em ação" no campo público da assistência em saúde mental. Rev. Latinoam. Psicopat. Fund., IX(2), 318-338.

Wiggershaus, R. (2002). Escola de Frankfurt - história, desenvolvimento teórico, significação política. Rio de Janeiro: Difel.

Wenders, W. (diretor). (1987). Der Himmel über Berlin. [Asas do Desejo; DVD]. Berlin: Europa Filmes.

Winnicott, D.W. (1983). O ambiente e os processos de maturação. Estudos sobre a teoria do desenvolvimento emocional. Porto Alegre: Artes médicas.

Winnicott, D. W. (2000). Da pediatria à psicanálise: obras escolhidas. Rio de Janeiro: Imago Ed.

Winnicott, D.W. (2006). Os bebês e suas mães. São Paulo: Martins Fontes. 